
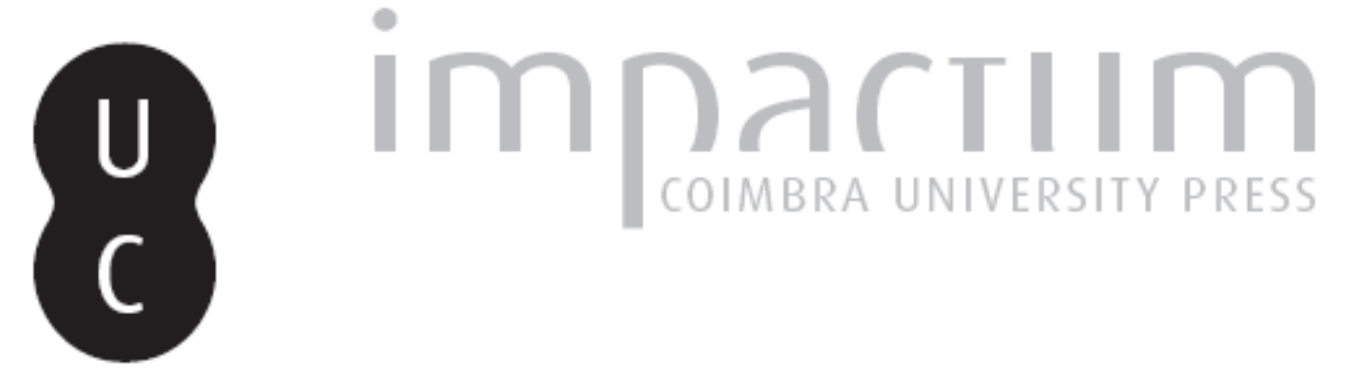

\title{
[Recensão a] Pierluigi Donini, II volto della luna. Introduzione, testo critico, traduzione e commento a cura di
}
Autor(es):
Lesage Gárriga, Luisa

Publicado por: International Plutarch Society

URL persistente:

URI:http://hdl.handle.net/10316.2/36355

DOI:

DOI:http://dx.doi.org/10.14195/0258-655X_10_7

Accessed : $\quad$ 26-Apr-2023 09:36:15

A navegação consulta e descarregamento dos títulos inseridos nas Bibliotecas Digitais UC Digitalis, UC Pombalina e UC Impactum, pressupõem a aceitação plena e sem reservas dos Termos e Condições de Uso destas Bibliotecas Digitais, disponíveis em https://digitalis.uc.pt/pt-pt/termos.

Conforme exposto nos referidos Termos e Condições de Uso, o descarregamento de títulos de acesso restrito requer uma licença válida de autorização devendo o utilizador aceder ao(s) documento(s) a partir de um endereço de IP da instituição detentora da supramencionada licença.

Ao utilizador é apenas permitido o descarregamento para uso pessoal, pelo que o emprego do(s) título(s) descarregado(s) para outro fim, designadamente comercial, carece de autorização do respetivo autor ou editor da obra.

Na medida em que todas as obras da UC Digitalis se encontram protegidas pelo Código do Direito de Autor e Direitos Conexos e demais legislação aplicável, toda a cópia, parcial ou total, deste documento, nos casos em que é legalmente admitida, deverá conter ou fazer-se acompanhar por este aviso.

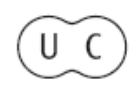




\section{Ploutarchos, n.s.}

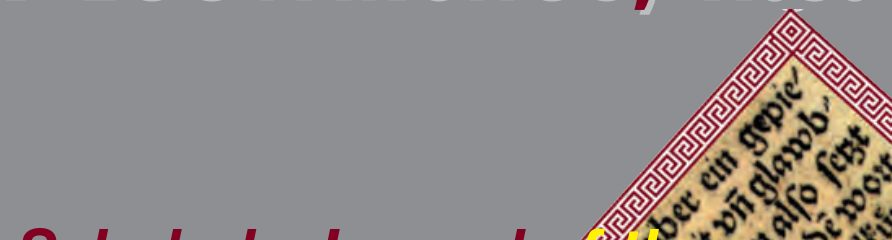

Scholarly Journal or (5) $x, 30$

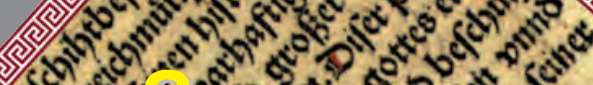

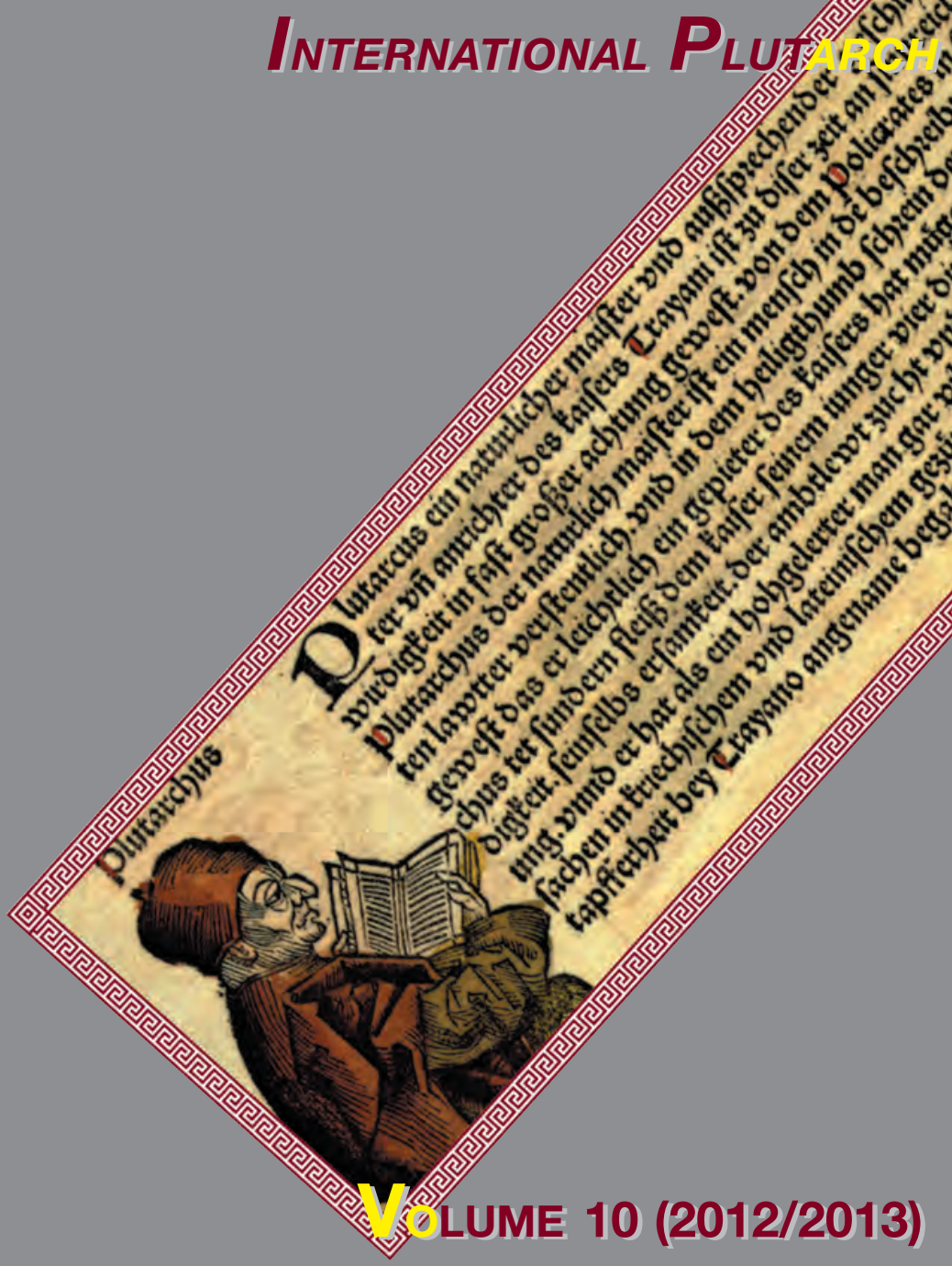

University of Málaga (Spain) Utah State University, Logan, Utah (U.S.A.) 
mente, se aborda la figura del pedadogo. Para terminar, en el epígrafe dedicado a los espacios de formación, dejando de lado las alusiones a la casa y a la escuela, se atiende a otros espacios públicos que desempeñan un papel crucial en la formación de los futuros ciudadanos: gimnasio, palestra y estoa, que dan pie a que Plutarco exprese su opinión sobre el homoerotismo que tantas veces los tuvo como escenario.

Una actualizada bibliografía y unos completos índices cierran este estudio que es, sin duda, un valioso instrumento tanto para los plutarquistas como para los investigadores, cada vez más numerosos, interesados en la infancia en la Antigüedad Clásica.

Marta González González Universidad de Málaga

Pierluigi Donini, Il volto della luna. Introduzione, testo critico, traduzione e commento a cura di - (Corpus Plutarchi Moralium, 48), M. D'auria Editore, Napoli, 2011, 368 pp. [ISBN 978-88-7092-324-7].

Nos encontramos ante un volumen más (el 48) de la prestigiosa colección italiana, iniciada por los Prfes. Gallo y Laurenti y continuada por Gennaro D'Ippolito, Amneris Roselli y Paola Volpe Cacciatore. En este caso se trata de un opúsculo plutarqueo de carácter científico y místico-filosófico que encierra notables dificultades tanto por su contenido como por el carácter restringido de su transmisión manuscrita. En cuanto al editor, traductor y comentarista, Pierluigi Donini, es Profesor de Historia de la Filosofía Antigua en la Universidad de Milán y ya publicó, hace dos años, una traducción comentada del tratado (De facie quae in orbe lunae apparet) que ahora edita y que es objeto de la presente reseña. Un tratado que, si bien ha despertado la curiosidad de algunos eruditos a lo largo de los siglos, ha quedado ligeramente rezagado frente a la atención que han recibido otros tratados de este autor del s. I d. C. Esto bien podría deberse a la complejidad del tema y de la estructura que presenta. La obra ha sido tradicionalmente dividida en dos partes netamente diferenciadas. La primera es de carácter científico: en ella los participantes en una reunión de amigos exponen y refutan las distintas teorías que existen con relación a la naturaleza de la luna -su luminosidad, peso, distancia respecto de la Tierra y el sol, fenómeno del eclipse, etc. La segunda es de naturaleza mítico-alegórica y pretende explicar la finalidad de este astro -que será de tipo escatológico. Estos dos bloques quedan ligados por una fase de transición que, alejándose de postulados puramente científicos, plantea cuestiones tales como la posible habitabilidad de la luna, que acabarán derivando en el mito final del tratado. Resulta fácil advertir la dificultad intrínseca al contenido y la problemática que surge al intentar encontrar un único sentido que aúne las dos secciones de la obra. Ésta es, precisamente, la intención que persigue $\mathrm{P}$. Donini en su nuevo libro.

$\mathrm{Su}$ trabajo cuenta con una ventaja, puesto que supone la revisión y ampliación de estudios anteriores donde el estudioso ya había expuesto sus consideraciones respecto de este autor y su obra. Y es que hace ya más de dos décadas que Donini dedica sus esfuerzos a esclarecer las dificultades filosóficas que los distintos tratados de los Moralia suponen para cualquier erudito. Esta dedicación, así como la seriedad y la profundidad de las que suele hacer gala en sus investigaciones, avalan la obra que ahora nos presenta.

El libro se estructura en tres bloques bien diferenciados: «Introducción» (pp. 7-109), «Traducción» (pp. 123-245) y «Comentario a la traducción» (pp. 247-364). Entre los dos primeros, el autor incluye dos breves subapartados: una bibliografia de la literatura citada en la introducción (pp. 111-119) -de 
gran utilidad, pues reúne los más destacables y recientes trabajos sobre este tratado- y una lista de las abreviaturas que ha utilizado (p. 121).

La introducción se divide en dieciocho apartados numerados en los que presenta el tratado, las dificultades de comprensión que ha supuesto para quienes se han aproximado a él y su propuesta de interpretación -en este caso, desde un punto de vista más filosófico que literario.

Comienza directamente (apartado 1) con el problema de la datación del tratado y presenta (ap. 2) los problemas de interpretación que ha supuesto el principio del mismo, puesto que se encuentra mutilado. Esta situación nos obliga a cuestionarnos hasta qué punto Plutarco se identifica con las opiniones que los personajes principales -Lamprias y Lucio-defienden.

Repasa asimismo (ap. 3) las diferentes interpretaciones a que se ha visto sometida la obra a lo largo de los años. Sin desprestigiar ninguna de ellas, Donini considera que todas «soffrono dell'unilateralità della prospettiva da cui sono condotti» (p. 20), es decir, ninguna ha conseguido llevar a cabo un estudio complexivo del De facie y de sus dos partes tan-aparentemente- distintas.

Será entonces (ap. 4) cuando presente el objetivo de su investigación: un estudio histórico-filosófico que funda ambas partes y les de un sentido unitario. Este trabajo requería un análisis exhaustivo de todos los estudios que ya habían contemplado el tratado desde un punto de vista filosófico. Análisis que le ha llevado a extraer un prejuicio recurrente en todos ellos: la consideración de Plutarco como uno de los máximos representantes del pensamiento ecléctico atribuido a su tiempo. Como aclara el autor, actualmente ya no se tiende a etiquetarlo de este modo y, por ello, se ha propuesto investigar en qué medida la obra de Platón y el medio y nuevo platonismo influyen en el De facie, para comprender así su auténtico significado.
Para ello revisa (apartados 5 y 6) la posición de Plutarco como académico, en concreto su posición con respecto a la Academia Nueva, y analiza cómo se refleja ésta en el De facie (ap. 7). Verbi gratia, el hecho de que la teoría defendida por Lamprias y Lucio -a grandes rasgos académica y que generalmente se atribuye al propio Plutarcopresente incongruencias o lagunas y no llegue a ser aceptada por los demás interlocutores como la «Verdad», parece acorde con la actitud filosófica de Plutarco y la Academia: una prudente postura que no da por verdadero aquello que no puede ser verificado y que prefiere adoptar la hipótesis más plausible entre aquellas con las que se cuenta.

Pero Donini no olvida la influencia que también Aristóteles ejerció sobre Plutarco, y analiza el tratado en su búsqueda, tal como ha hecho con la influencia del academicismo (ap. 8).

Será en los siguientes apartados (9-10) cuando nos haga partícipes de todo lo que el estudio de la compleja personalidad filosófica de Plutarco revela acerca del sentido del De facie. La falta de congruencia y de conclusión en las argumentaciones de la parte científica del tratado mencionadas líneas arriba indican, en realidad, que Plutarco no se preocupaba exclusivamente por la «verdad científica» en sí misma: según sus creencias, un tema como el de la luna no atañe únicamente a la esfera física, sino también a la divina, y por tanto ningún argumento científico será suficiente para explicar su naturaleza. Como afirma Donini, «Senza affatto essere o diventare un critico radicale della scienza, della logica, della razionalità, Plutarco riesce a suggerire i limiti che a tutte queste attività e funzioni sono per un platonico inevitabilmente inerenti» (p. 62).

Es necesario recurrir a otro procedimiento para explicar esa naturaleza: el mito. En los apartados que siguen (11-14) el autor explica la utilidad que presenta el mito para continuar la línea filosófica que Plutarco 
deja entrever ya en la parte científica. Y es que mediante este recurso el de Queronea revisaría, ajustaría y, en algunos casos, desmentiría los datos de esa primera parte, pero no llegaría tampoco a una conclusión única y cerrada: al modo platónico, deja la interpretación del mito abierta a sus lectores, sin establecer una posición dogmática. Parece que «esorta implicitamente a non fidarsi troppo della scienza, [...] ma anche a non assumere il mito come l'espressione di una verità letterale» (p. 73). Donini entiende que el objetivo del tratado en su conjunto no es identificar la naturaleza de la luna, sino que utiliza este tópico como pretexto para tratar un tema más complejo aún: los límites del conocimiento humano. En el plano físico la ciencia se ve limitada por las pruebas (o la falta de ellas, más bien) y en el plano metafísico y teológico el ser humano no tiene la capacidad de comprender la «Verdad» en su totalidad, tan sólo puede intuir y tener fe.

El estudioso italiano llega también a otra conclusión (ap. 15-17). El diálogo que nos ocupa tiene demasiadas coincidencias con otro tratado de Plutarco, De defectu oraculorum, como para no detenerse en un estudio comparativo de ambos. Sugiere que las dos obras podrían haber formado, en las intenciones de Plutarco, un conjunto, un todo. A través de numerosas analogías -la temática de ambos gira en torno a un problema de naturaleza física y divina a la vez, ninguno llega a establecer una solución definitiva para el problema planteado, se invita al lector a una posterior reflexión personal, etc.-, Donini va demostrando que su teoría tiene fundamento y que «ciascuno dei due scritti diventa ancor più ricco, più interessante e filosoficamente significativo se è letto a complemento e integrazione dell'altro» (p. 94).

En el último capítulo de la introducción trata brevemente los manuscritos que han conservado el tratado y afirma que su edición no tiene intención de ser considerada crítica: se ha limitado a elegir entre las variantes que le han parecido más acertadas en las ediciones de Pohlenz (1955) y Cherniss (1957). Dicho esto, una lectura atenta de su traducción revela cierta preferencia por el segundo editor.

De su labor como traductor cabe destacar la fluidez con la que se lee el tratado, bastante complejo en su lengua original tanto por la dificultad del tema como por el estilo de Plutarco. Considero digna de elogio la capacidad de Donini para conseguir una versión llana y actual que, no obstante, se mantiene próxima a la sintaxis del original. Este logro, creo, es el reflejo de los años de estudio que el profesor ha dedicado a Plutarco y a este tratado en concreto.

Y como aliciente para el lector versado en la tradición clásica o, al menos, en griego antiguo, su traducción viene acompañada del texto griego «a fronte» y de un aparato crítico que refleja las variantes más significativas sobre pasajes corruptos o de difícil interpretación, incluyendo a veces tomas de posición y propuestas propias basadas casi siempre en criterios de sentido y filosóficos.

El comentario a la traducción, el tercer bloque, se presenta al final del libro a modo de notas. Dada la cantidad (439), considero que se trata de una buena elección, puesto que si se hubiera dispuesto como notas a pie, se habría interrumpido una lectura continuada del tratado -así las ha dispuesto en su introducción, pese a que también son numerosas (225) y a que la longitud de algunas, cuya información bien podría haberse integrado en el cuerpo del texto, hace que se pierda el hilo de lo que decía. Las notas del comentario, que sirven para facilitar y completar la compresión del tratado, son de carácter diverso: de tipo filológico, filosófico, histórico, etc. Por ejemplo, Donini aprovecha las notas para explicar un fragmento confuso, para referenciar una cita que Plutarco usa en su 
redacción o, incluso, para presentar a los personajes que van apareciendo a lo largo del tratado, debido a que no ha dicho nada acerca de ellos en la introducción.

De hecho, quizá podría haber incluido una pequeña presentación de la obra antes de plantear el análisis tan específico que ha llevado a cabo, pues para un lector que no esté previamente familiarizado con el tratado, la introducción puede resultar de ardua comprensión. Para el lector especializado, sin embargo, el saber tan amplio y profundo que Donini pone en juego sobre ella en este primer bloque permite seguir su hilo argumental y sus ideas con gran facilidad. Es cierto que a partir del noveno apartado -donde Donini ofrece gran cantidad de información nueva y aparentemente poco conexa- resulta más difícil entender a dónde nos quiere llevar, pero, quizá por esa confusión momentánea, resulta muy gratificante descubrir sus conclusiones en los últimos apartados.

A este respecto conviene mencionar que no sólo es profundo su conocimiento del tratado; también lo es el de sus fuentes: han sido bien trabajadas y asimiladas, como reflejan las notas de la introducción. Resulta, además, muy profesional por su parte no asumir como ciertas e irrevocables aquellas opiniones con las que coincide, pues su experiencia en el mundo de la investigación le aconseja prudencia en estos casos: tal como hiciera Plutarco, se atiene a lo que parece más plausible cuando no cuenta con la verdad absoluta sobre una determinada cuestión.

Luisa Lesage GÁRriga Universidad de Málaga.

\section{J. Beneker, The Passionate Statesman: Eros and Politics in Plutarch's Lives, Ox- ford, OUP, 2012, XII + 258 pp. ISBN 978-0- 19-969590-4.}

El libro de Jeffrey Beneker, profesor de Clásicas en la Universidad de Wisconsin y buen conocedor de la tradición biográfica de la Antigüedad, estudia las conexiones entre pasión y política en las Vidas paralelas de Plutarco, centrándose en algunas de las parejas de griegos y romanos más importantes (Alejandro-César; Demetrio-Antonio; Agesilao-Pompeyo) para examinar el modo en que trata Plutarco conceptos como la amistad o el cariño ( $\varphi$ ı $\lambda$ í $\alpha)$ y sobre todo el deseo erótico ( sus biografías la narración de los asuntos eróticos privados de sus personajes, en la idea de que este tratamiento -y por supuesto la aplicación del sistema ético que conlleva, que debe mucho a Platón pero también a Aristóteles- incide tanto en la redacción de sus biografías como en su lectura e interpretación de los hechos históricos.

Tras una breve introducción (pp. 1-6) en que se traza a grandes rasgos el plan de la obra haciendo un resumen del contenido de cada capítulo y subrayando el especial interés de Plutarco en la noción de ěp $\omega \varsigma$, se pasa a definir el trasfondo filosófico que se desprende de este enfoque y de su aplicación a la narración histórica. Así, en el capítulo 1 ("Erōs and Marriage", pp. 7-57), Beneker expone las opiniones del Queronense sobre la virtud moral, el amor y el deseo, recurriendo principalmente a sus tratados Virt. mor. y Amat., y trata de demostrar cómo se combinan en él la concepción platónica del alma y la noción aristotélica de la amistad

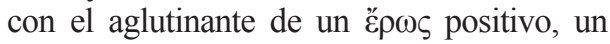
deseo moderado y dosificado por la razón, como se desprende, en concreto, de su descripción del matrimonio ideal, y de las relaciones heterosexuales en general, sobre la base de un amor mutuo ( $\varphi$ i $\lambda i ́ \alpha)$ de los perso-

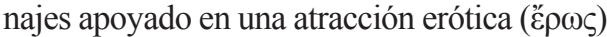
sólida y duradera, ilustrado por los ejemplos de Bruto y Porcia o de Pericles y Aspasia. En el capítulo 2 ("Moral Virtue, Erōs, and History", pp. 58-102), Beneker introduce el concepto de "reconstrucción histórico-ética", que Plutarco habría seguido como una especie de principio 